\title{
Analyze of Saliva Cortisol as Biomarker in Healthy Distressed Subjects
}

\author{
ADELA MAGDALENA CIOBANUㄴ, MARIUS TOMA PAPACOCEA², ALEXANDRA IOANA MIHAILESCU ${ }^{3}$, MIRELA MANEA4, \\ IOANA ANCA BADARAU ${ }^{5}$, IOANA RALUCA PAPACOCEA ${ }^{5 *}$, AUREL NIRESTEAN ${ }^{6}$, MIHNEA COSTIN MANEA ${ }^{4}$, OVIDIU POPA VELEA ${ }^{3}$ \\ ${ }^{1}$ Carol Davila University of Medicine and Pharmacy, Faculty of Medicine, Discipline of Psychiatry, Prof dr. Al. Obregia Clinical \\ Hospital, 10 Berceni Str. 041914, Bucharest, Romania \\ ${ }^{2}$ Carol Davila University of Medicine and Pharmacy, Faculty of Medicine, Neurosurgical Department of the St. Pantelimon Clinical \\ Emergency Hospital, 340-342 Pantelimon Sos., 021659, Bucharest, Romania \\ ${ }^{3}$ Carol Davila University of Medicine and Pharmacy, Faculty of Medicine, Discipline of Medical Psychology, 8 Eroii Sanitari Blvd, \\ 050474, Bucharest, Romania \\ ${ }^{4}$ Carol Davila University of Medicine and Pharmacy, Faculty of Dental Medicine, Discipline of Psychiatry and Psychology, Prof. \\ dr. Al. Obregia Clinical Hospital, 10 Berceni Str. 041914, Bucharest, Romania \\ ${ }^{5}$ Carol Davila University of Medicine and Pharmacy, Faculty of Medicine, Discipline of Physiology I, 8 Eroi Sanitari Blvd, 050474, \\ Bucharest, Romania \\ ${ }^{6}$ University of Medicine and Pharmacy Tg. Mures, Discipline of Psychiatry, 38 Gh. Marinescu Str, 540072, Tirgu-Mures, Romania
}

Stress investigation especially in young healthy adults is a main mental health issue due to its individual and social consequences on long term. In order to characterize physiological, pathological and biochemical mechanisms of stress response, several biomarkers were proposed. Among these, the evaluation of the salivary biomarkers represents a fast and simple procedure, both in healthy subjects and patients. Saliva contains a wide range of parameters reflecting physiologic endocrine and immune responses, such as biologically active form of certain hormones (e.g. cortisol), growth factors, immune molecules. The present article is focused on cortisol evaluation as possible biomarker of stress and its analyze in the context of literature data.

Keywords: saliva, cortisol, stress, anxiety

Vulnerability to stress, expressed by emotional distress (symptoms of anxiety and depression), has also as endocrine expression, through the modification of hypothalamo-pituitary-adrenal axis (HPA) parameters, most commonly studied being cortisol secretion [1]. Chronic stress may lead to both increase and decrease in cortisol levels in general population [2,3]. Even though cortisol and its derivatives are beneficial as antiinflammatorydrugs, and can be used in a variety of medical conditions [4,5], chronic emotional distress in young healthy adults persistently activates the HPA, this being translated into an exaggerated sympathetic response and cortisol increase at subjects exposed to general stressors $[6,7]$.

Salivary cortisol analysis has been consistently reported in literature to be advantageous, because of the availability of the assay kit and the ease with which the samples are collected and analyzed. These factors may be important in terms of the costs-benefit ratio, when analyzing large groups of subjects.

The measurement of salivary cortisol is a noninvasive technique very often used in the study of cortisol secretion patterns in young subjects. Saliva measurements are relevant for several pathologies $[8,9,10]$, while salivary cortisol and the serum cortisol correlate significantly. Reported values in clinically healthy adults lie between $0.94-15.51 \mathrm{ng} / \mathrm{dL}$ (in women between 21 and 30 years) and between 2.72-13.48 ng / $\mathrm{dL}$ (in men aged 21-30) [10, 11].

\section{Experimental part}

Material and methods

The design of the study was mixed (cross-sectional and longitudinal). Study population comprised first year students, having participated at one of the exams of the winter session, mandatory for all students. The study was approved by the Ethic Committee of the University of Medicine and Pharmacy Carol Davila. All subjects provided an informed consent regarding participation in this study and they were not paid or rewarded for the participation in the study.

Saliva samples were collected in basal conditions from 95 healthy volunteers, between 18- 35 years old, from both genders. Emotional distress was quantified by measuring self-rating anxiety and depression symptoms in the periods before the examination session (in no-stress conditions) and during the examination session period (stress conditions).

The participants were instructed not to eat, to brush their teeth, and not to smoke 30 minutes before sampling. Saliva samples were centrifuged at $3500 \mathrm{rpm}$ for 15 minutes and supernatant was used for cortisol determination. Concentration of salivary cortisol was determined using NOVATEC ELISA immunochemistry assay, and expressed values in units of $\mathrm{ng} / \mathrm{mL}$.

Beside the assessment of the salivary cortisol during stressful periods, all participants were administered the following psychometric instruments: Perceived Stress Scale (PSS), the Zung Self-Rating Anxiety Scale (ZSAS) and the Zung Self-Rating Depression Scale (ZSDS).

Statistical analysis was performed using the SPSS version 16 software. Parametric (tand Kruskal Wallis) tests and non-parametric (Spearman correlation) tests were performed, in order to capture the associations between the dependent and independent variables. Statistical significance level was set at $p<0.05$. 


\section{Results and discussion}

We found no significant statistical correlations between cortisol levels and perceived stress scores in stressful ( $\mathrm{rS}=$ .154) or in non-stressful circumstances ( $\mathrm{rS}=-.154)$; anxiety scores in stressful ( $\mathrm{rS}=-.137)$ or in non-stressful circumstances $(\mathrm{rS}=-.094)$; depression score in stressful $(r S=-.047)$ or in non-stressful circumstances $(r S=-.051)$.

When separating the groups, according to the score obtained at the Zung Self-Rating Depression Scale-ZSDS(cut-off score 48, corresponding to a moderate and severe intensity of depression), we noticed a trend of cortisol to increase in mild and severe depression (mean for the whole sample: for ZSDS $\geq 48: 7.48 \mathrm{ng} / \mathrm{dL}$; for ZSDS < 48: $6.88 \mathrm{ng} /$ $\mathrm{dL})$, though without significance ( $\mathrm{t} 93=1.025, \mathrm{p}=0.308$ ).

Analyzing cortisol levels and depression and/or anxiety in stressful periods, people with depression display the lowest level of cortisol, however the differences were not statistically significant $(\chi 2(3)=3.313, p=0.346)$.

The values obtained in young adult medical students were within the normal range, and salivary cortisol did not present statistically significant differences over the mean interval (table 1, fig 1).

No significant correlations between absolute cortisol levels and emotional distress scales (Zung Anxiety, Zung
Depression and Perceived Stress Scale) were observed, so in the case of a representative sample of young adult medical students, emotional status did not significantly affect the response of the HPA cortex in stress, namely in the pre-session and/or session periods (table 2, fig. 2).

Cortisol values obtained from young adult medical students were within the normal range reported, with no statistically significant differences in the mean of the interval.

It can be noticed that the difference between salivary cortisol by gender were notstatistically significant, but there is a tendency for higher salivary cortisol stress in women than men, which is consistent with literature data [12].

No significant correlations were identified between saliva cortisol levels and emotional distress, evaluated through anxiety scale. This leads to the conclusion that in the case of a representative sample of young adult medical students, emotional status does not significantly affect the response of the HPA cortex in stress [13,14].

Results showed salivary cortisol with higher values in young adults with stressful life events and symptoms of depression (fig. 2), reported after stressful events. This is consistent with literature data.

\begin{tabular}{|l|l|l|l|l|l|l|}
\hline & N & \multicolumn{2}{|l|}{ Mean } & SD & \multicolumn{2}{l|}{ CI 95\% of the mean } \\
\hline & Statistic & Statistic & Standard Error & Statistic & Inferior & Superior \\
\hline Cortisol & 95 & 7.01 & 0.23 & 2.30 & 6.54 & 7.48 \\
\hline Male & 22 & 6.91 & 0.48 & 2.26 & 5.90 & 7.91 \\
\hline Female & 73 & 7.04 & 0.27 & 2.32 & 6.49 & 7.58 \\
\hline
\end{tabular}

Table 1

SALIVA CORTISOL VALUES BEFORE EXAM (BASAL STATE)

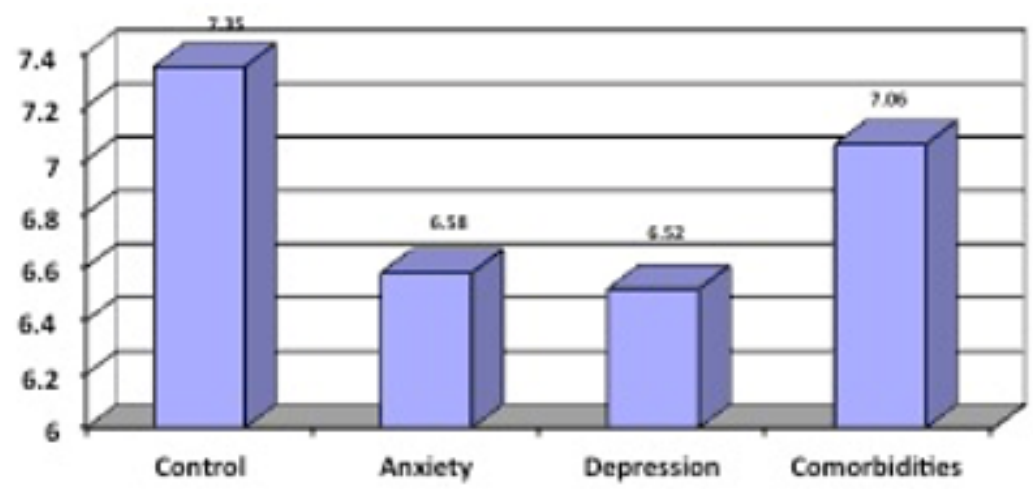

\begin{tabular}{|c|c|c|c|c|c|c|}
\hline & \multirow{2}{*}{$\mathrm{N}$} & \multirow{2}{*}{ Mean } & \multirow{2}{*}{ SD } & \multirow{2}{*}{$\begin{array}{l}\text { Standard } \\
\text { Error }\end{array}$} & \multicolumn{2}{|c|}{ CI $95 \%$ of the mean } \\
\hline & & & & & Inferior & Superior 7 \\
\hline no $\mathrm{DE}$ pre-session no $\mathrm{DE}$ session & 8 & 8.16 & 1.36689 & 0.48327 & 7.0197 & 9.3053 \\
\hline no $\mathrm{DE}$ pre-session and $\mathrm{DE}$ session & 11 & 7.70 & 1.21 & 0.36 & 6.89 & 8.52 \\
\hline DE pre-session and DE session & 27 & 8.09 & 2.32 & 0.44 & 7.17 & 9.00 \\
\hline $\mathrm{DE}$ pre-session, no $\mathrm{DE}$ session & 3 & 7.36 & 0.46 & 0.26 & 6.21 & 8.51 \\
\hline Total & 49 & 7.97 & 1.88 & 0.26 & 7.42 & 8.51 \\
\hline
\end{tabular}

Fig. 1 Cortisol values in study group before exam (basal state)
Table 2

SALIVA CORTISOL IN THE PRESENCE OF EMOTIONAL DISTRESS (PRE-SESSION AND EXAM SESSION) 


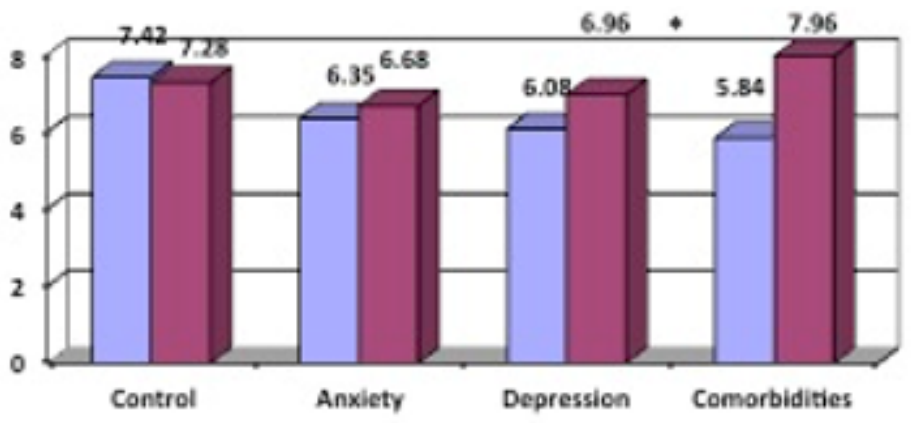

Fig. 2 Mean values of salivary cortisol in the presence of stressful event (after exam)
These statistically insignificant results can be added to the studies that reportthe lack of correspondence between anxiety and the evaluations of salivary cortisol [15].

\section{Conclusions}

The biological factor, cortisol, does not statistically associate with emotional distress in this particular studied group. Instead, we identified a tendency of increased values in the subjects with high severity of symptoms of anxiety and a significant increase in cases with symptoms of depression. These heterogeneous results suggest the need to continue the case-control lot studies in different environmental situations, possibly within a multiple dose cortisol analysis protocol.

\section{References}

1.SMEETS, T., VAN RUITENBEEK, P., HARTOGSVELD, B., QUAEDFLIEG, C. W. Brain cogn., 133, 2019, p. 60-71.

2.BALLHAUSEN, N., KLIEGEL, M., RIMMELE, U. Neurobiol. Learn. mem., 161, 2019, p.169-174.

3.FIKSDAL, A., HANLIN, L., KURAS, Y., GIANFERANTE, D., CHEN, $X$., THOMA, M. V., ROHLEDER, N. Psychoneuroendocrinology, 102, 2019, p. 44-52.

4.PAPACOCEA, T., POPA, E., TURLIUC, D., PAPACOCEA, R. Farmacia, 67, no. 1, 2019, p. 140-145.
5.CASTRO, M., ELIAS, L. L., ELIAS, P. C., MOREIRA, A. C. (2003). Clin endocrinol., 59, no.6, 2003, p.800-805.

6.BALABAN, M., VIRGOLICI, B., DINU, A., TOTAN, A., MIRICESCU, D., STEFAN, D., GREABU, M., MOHORA, M. Rev Chim (Bucharest), 70, no.4, 2019, p.1315-1318.

7.PAPACOCEA, I. R., BADARAU, I. A., CIORNEI, M. C., BURCIULESCU LIDER, S. Rev Chim (Bucharest), 70, no.4, 2019, p.1445-1448.

8.BALAN, D. G., SIANU, D. P., STANESCU, I. I., IONESCU, D., BALCANGIU, A. E. S., RADUCU, L., TARMURE, V. Rev Chim (Bucharest), 69, no.5, 2018, p.1125-1128.

9.STONE, A. A., SCHWARTZ, J. E., SMYTH, J ., KIRSCHBAUM, C., COHEN, S., HELLHAMMER, D., GROSSMAN, S. Psychoneuroendocrinology, 26, no.3, 2001, p. 295-306.

10.CIOBANU, A. M., POPA, C., MARCU, MADALINA, CIOBANU, C. F. Rom J Morphol Embryol. 55, no.1, 2014 p.189-195.

11.KIRSCHBAUM, C., HELLHAMMER, D. H. Neuropsychobiology, 22, no.3, 1989, p.150-169.

12.VAN DEN BOS, R., HARTEVELD, M., STOOP, $\mathrm{H}$.

Psychoneuroendocrinology, 34, no.10, 2009, p.1449-1458.

13.HORI, H., OZEKI, Y., TERAISHI, T., MATSUO, J., KAWAMOTO, Y., KINOSHITA, Y., KUNUGI, H. J Psych Res, 44, no.14, 2010, p. 865-873. 14.DIEMER, J. Psychoneuroendocrinology, 82, 2017, p. 187-188. 15.CASTALDO, R., XU, W., MELILLO, P., PECCHIA, L., SANTAMARIA, L., JAMES, C. 38th Ann International Conf. IEEE Eng. Med. Biol. Soc. (EMBC), 2016, p. 3805-3808

Manuscript received:17.12.2018 